\title{
Associations Among Selective Attention, Memory Bias, Cognitive Errors and Symptoms of Anxiety in Youth
}

\author{
Sarah E. Watts • Carl F. Weems
}

Published online: 13 March 2007

(C) Springer Science+Business Media, LLC 2007

On page 7 , in the first section of the results in the preliminary analyses section, the last sentence of the last paragraph of that section, the following error was inadvertently made:

Results of $t$-tests indicated that African American and Euro-American participants only significantly differed on CNCEQ catastrophizing [African American $M=13.16$ $(S D=5.5)$; Euro-American $M=11.01(S D=4.0) ; t(\mathbf{1 2 0})=$ $2.46, p<.05]$.
The sentence should read:

Results of $t$-tests indicated that African-American and Caucasian participants only significantly differed on CNCEQ Catastrophizing [African-American $M=13.80$ $(S D=5.17)$; Caucasian $M=11.18(S D=4.01) ; t(70)=$ $2.41, p<.05]$.

The online version of the original article can be found at: http://dx.doi.org/10.1007/s10802-006-9066-3

S. E. Watts · C. F. Weems $(\square)$

Department of Psychology, University of New Orleans,

New Orleans, LA 70148, USA

e-mail: cweems@uno.edu 